\title{
ВСЕРОССИЙСКАЯ НАУЧНАЯ КОНФЕРЕНЦИЯ «КУЛЬТУРА МЕЖДУ ЛОГОСОМ И МИФОМ: К ПРОБЛЕМЕ БЕССОЗНАТЕЛЬНОГО» (К 80-ЛЕТИЮ А. Э. ВОСКОБОЙНИКОВА)
}

\author{
Ч. К. Ламажаа, А. В. Костина \\ Московский гуманитарный университет
}

Аннотация: В статье представлен обзор работы Всероссийской научной конференции «Культура между Логосом и Мифом: к проблеме бессознательного", которая прошла в Московском гуманитарном университете 26-27 октября 2017 года и была посвящена 80-летию А. Э. Воскобойникова.

Ключевые слова: обзор; бессознательное; Московский гуманитарный университет; юбилей; А. Э. Воскобойников; научная школа

\section{ALL-RUSSIAN SCIENTIFIC CONFERENCE “CULTURE BETWEEN LOGOS AND MYTH: ON THE ISSUE OF THE UNCONSCIOUS” (ON THE EIGHTIETH BIRTHDAY OF A. E. VOSKOBOYNIKOV)}

\author{
Ch. K. Lamazhaa, A. V. Kostina \\ Moscow University for the Humanities
}

Abstract: The paper presents a review of the work of the All-Russian Scientific Conference "Culture between Logos and Myth: on the Issue of the Unconscious", held at Moscow University for the Humanities on 26-27 October 2017 and devoted to the eightieth birthday of A. E. Voskoboynikov.

Keywords: review; unconscious; Moscow University for the Humanities; jubilee; A. E. Voskoboynikov; scientific school

26-27 октября 2017 г. в Московском гуманитарном университете прошла Всероссийская научная конференция «Культура между Логосом и Мифом: к проблеме бессознательного», которая была посвящена 80-летию доктора философских наук, профессора Анатолия Эммануиловича Воскобойникова, одного из старейших преподавателей университета. Сам юбилей отмечался 27 августа текущего года, и А. Э. Воскобойников был отмечен Орденом «Служение и честь» I степени, которым награждаются сотрудники университета за значительные заслуги перед университетом. А. Э. Воскобойников является видным ученым и философом, посвятив- 


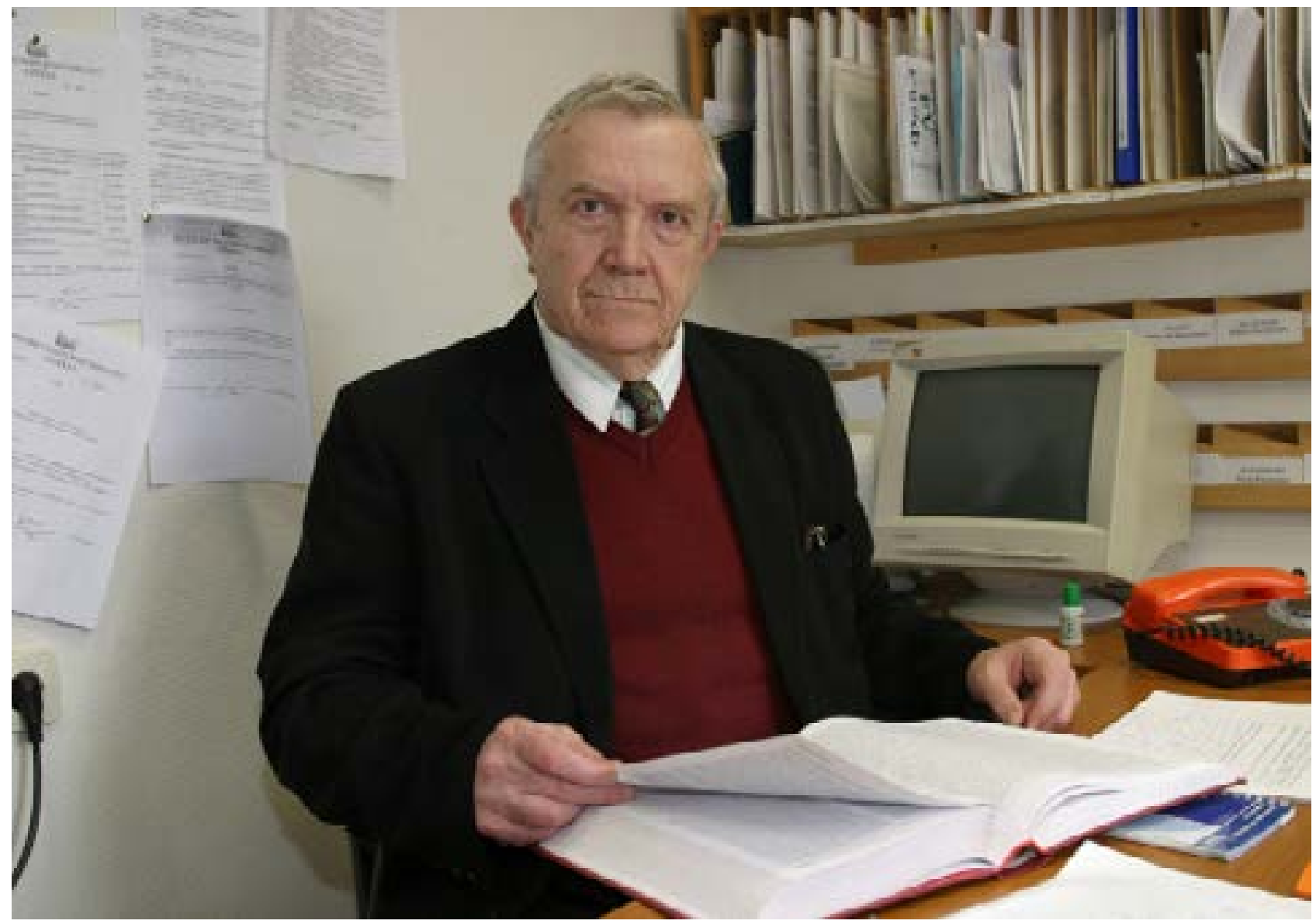

шим свою исследовательскую деятельность проблеме бессознательного. Эта тема стала центральной и на данной конференции - ее участники не только констатировали вклад в развитие этой проблематики профессора А. Э. Воскобойникова, но затронули в своих докладах те вопросы, которые сегодня являются актуальными для философии психоанализа, а также обозначили направления, в границах которых проблема бессознательного развивается сегодня.

26 октября в зале заседания ученого совета университета пленарное заседание открыл ректор Московского гуманитарного университета, доктор философских наук, профессор И. М. Ильинский. Он сказал, что знаком с А. Э. Воскобойниковым с 1968 года, когда работал в ЦК ВЛКСМ и занимался кадровыми вопросами, в том числе для Центральной комсомольской школы (ныне - МосГУ). Анатолий Эммануилович пришел тогда в это учебное заведение и остался здесь на всю жизнь. И он не только продолжает преподавать в этом университете (без малого 50 лет!), но и все эти годы занимается одной темой - проблемой бессознательного. Однако Университет А. Э. Воскобойников заканчивал словсем по другой специальности. Все настолько привыкли к тому, что он - философ, что мало кто помнит и знает его первую специальность - «астроном» (см.: Ламажаa, 2007). «Он один из самых упорных, настойчивых, умных людей нашей страны», - 
высказался о философе Игорь Михайлович, считая большой удачей для университета долгую и плодотворную работу Анатолия Эммануиловича здесь. Ректор назвал юбиляра как минимум «достоянием Университета» по аналогии с «национальным достоянием России», в качестве которого выступает все лучшее, чем может гордиться наша страна.

В выступлении доктора философских наук, профессора, ректора Национального института бизнеса С. И. Плаксия, который в далекие 1970-е гг. слушал лекции философа в качестве студента, отмечалось, что А. Э. Воскобойников был одним из самых ярких профессоров в период его студенчества, который он прошел вместе с В. А. Луковым, директором Института фундаментальных и прикладных исследований МосГУ. «Философами называться могут многие, но настоящие философы - это “штучный товар”, -- сказал он. - И не каждого преподавателя философии будут любить и ценить. На лекции Анатолия Эммануиловича студенты ходить любили, аудитория была всегда полной. Педагог он терпеливый и вдумчивый, умеющий донести свою мысль до слушателей. Поэтому для Московского гуманитарного университета его Почетный профессор, каковым является А. Э. Воскобойников, - настоящее богатство».

Отвечая на эти и ранее прозвучавшие в августе поздравления, А. Э. Воскобойников сердечно поблагодарил выступавших и в шутку сказал, что хотел бы познакомиться с тем человеком, которого так превозносят. Он выразил признательность коллегам за организацию такого «праздника мысли» и прочитал небольшую лекцию для аудитории, которая состояла действительно в значительной степени из его учеников, ныне кандидатов и докторов наук, его коллег.

Сфера интересов ученого - универсальная эволюция и философская антропология, пересекающиеся и во многом сегодня необходимые для человечества, поскольку усложнение социальной жизни обуславливает массу проблем. Рассуждая о бессознательном, сознательном и сверхсознательном в рамках указанных областей, А. Э. Воскобойников раскрыл тот аспект бессознательного, который является предметом его исследований в последние годы - это тема гениальности и ее проявлений в творчестве. По мнению профессора, бессознательное в творческом процессе проявляется очень активно, точно так же, как и сознательное. Причем, это касается не только эмоциональной сферы деятельности - прежде всего, искусства, - но и интеллектуальной - в том числе, научной. Сверхсознательное же - это та область, которая открывается только гениям, способным аккумулировать в своем творчестве огромный объем информации самого разного рода - от научной и художественной до обыденной, реализуя в своей деятельности те цели, к которым идет человечество. Ученый признался, что не только философия является для него любимой на- 
укой, но и психология для него - «возлюбленная», поскольку именно на их стыке и решаются проблемы бессознательного.

На конференции докладчики затронули в своих выступлениях самые разные аспекты проблемы бессознательного, в том числе, отмечая вклад А. Э. Воскобойникова в развитие данной тематики и его усилия по обогащению отечественной философской мысли. Так, ведущий научный сотрудник Государственного института искусствознания, кандидат искусствоведения, доктор культурологии Е. В. Сальникова посвятила доклад моделированию образов бессознательного в мировом кинематографе. По ее словам, обращение кино к проблеме бессознательного на протяжении XX века прошло ряд этапов в ее осмыслении: начиная с 1920-х гг., когда бессознательное и подсознание воспринимались как бездна; через 1960е гг., отмеченные новым интересом к этой теме, когда в авторском европеизированном кино стали активно использовать мотивы снов, видений, воспоминаний (бессознательного припоминания); и до рубежа XX-XXI веков, когда произошли радикальные изменения, и сами художники перестали верить в ценность внутреннего мира.

Заведующий лабораторией философии образования Института теории образования и педагогики РАО, доктор педагогических наук, профессор Я. С. Турбовской высказал определенные опасения по поводу превращению темы бессознательного в популярный дискурс. По мнению ученого, если исследователи проблемы имеют свою позицию по поводу предмета исследования, то они также должны осознавать и свою ответственность: «Наука может изучать все, что угодно, но надо нести ответственность за каждое сказанное слово». Как считает Я. С. Турбовской, исследование сферы бессознательного несет в себе угрозу получения власти над психикой человека, и само донесение результатов исследования до общественного сознания также чревато рисками. Поэтому к этой проблематике нужно относиться со всей ответственностью.

Профессор кафедры истории и философии образования педагогического факультета Московского государственного университета им. М. В. Ломоносова, доктор философских наук, профессор И. Г. Хангельдиева раскрыла тематику конференции в ее связи с педагогической деятельностью. Профессор показала, что одна из новейших образовательных технологий - а именно, эдьютеймент - основана на единстве сознательного и бессознательного, где обучение соединяется с развлечением.

Директор Института фундаментальных и прикладных исследований МосГУ, доктор философских наук, профессор В. А. Луков проанализировал проблему Мифа и Логоса как непосредственно связанную с проблемой тезауруса. На примере мифологии, сложившихся в современной культуре и связанной с именем Шекспира, он показал, что наш тезаурус, то есть, та 
часть культуры и знаний о мире, которая освоена нами, во многом строится также и на мифах, на мифологическом знании о тех или иных персонажах, личностях. В том числе, и о Шекспире, знание о котором тесно переплетается с общественным и нашим личным отношением к нему. Формирование тезаурусной сферы, в том числе, на основе мифологических представлений, непосредственно связано с работой нашего сознания.

Заведующий кафедрой международного сотрудничества Института менеджмента и маркетинга Российской академии народного хозяйства и государственной службы при Президенте РФ, доктор философских наук, профессор С. А. Семедов - первый аспирант А. Э. Воскобойникова - поделился своими воспоминаниями о первых шагах в науку под руководством профессора. В своей кандидатской диссертации он развил тему бессознательного, неосознанного в сфере межнациональных отношений, где большим влиянием обладает этнонациональная мифология.

К проблеме актуальной для сообщества или его сегмента мифологии обратился главный научный сотрудник Института культурного и природного наследия им. Д. С. Лихачева, доктор философских наук, профессор А. Я. Флиер. Он обратил внимание на то, что мифология выступает в качестве своеобразной совокупности феноменов окружающей реальности, которые становятся контекстом по отношению к самому тексту культуры, детерминируя интерпретацию культурных артефактов. Миф в классической трактовке - как сказания о героях и их деяниях - получил развитие в докладе доцента кафедры философии, культурологии и политологии Московского гуманитарного университета, кандидата исторических наук, доцента А.А. Зедгенидзе, раскрывшей историческую связь между мифом об Ифигении в Тавриде и святилищами Херсонеса Таврического.

Бессознательному не как индивидуальному, а как коллективному, влияющему на развитие культуры, посвящен анализ мифологической эпохи и ее ведущим константам, представленный ведущим научным сотрудником Института философии РАН, доктором философских наук А. А. Гореловым и профессором кафедры философии, культурологи и политологии Московского гуманитарного университета, доктором философских наук, профессором Т. А. Гореловой. Как было отмечено авторами, одним из источников культурной (духовной) энергии является жертва и сам ритуал жертвоприношения как «способ инициации культуры и ее вечного возрождения», как точка истории, ведущая к созиданию нового культурного кода.

Одной из важнейших областей, где бессознательное исследуется наиболее активно, является область медицины, а именно, клинической психологии, психоанализа и психотерапии, как было отмечено С. П. Бурцевым, профессором кафедры социологии Московского гуманитарного университета, кандидатом медицинских наук, доцентом. По его мнению, 
проблема бессознательного актуальна сегодня как никогда, она представляет интерес как феноменологический, так и познавательный, затрагивающий область не только естественнонаучную, но и философскую. Однако для дальнейшего исследования нервных процессов, осуществляющихся как на клеточном уровне, так и на уровне целостного организма, она серьезно нуждается в создании принципиально новой методологии.

Ведущей функцией бессознательного является формирование образов, аккумулирующихся в сновидениях. Как было показано И. С. Ивановой, доцентом кафедры философии, культурологии и политологии Московского гуманитарного университета, кандидата философских наук, доцента, сновидения обладают телеологичностью и самоценностью в качестве феноменов проявления творчества. Автор рассмотрела сновидения по принципу их связи с базовыми потребностями человека - в безопасности, любви и дружбе, самореализации.

Один из аспектов бессознательного связан с гендерной проблематикой. Докторант А. Э. Воскобойникова, доктор философских наук, кандидат технических наук М. В. Аристова посвятила свой доклад вопросу о существовании женщины между Логосом и Мифом, показав, что процесс женской эмансипации, способствовавший формированию относительно независимой женской личности, осуществляется в направлении от традиции, имеющей существенную мифологическую поддержку, к разуму, бывшему всегда прерогативой мужчин.

Особый интерес представили те позиции авторов, где проблема бессознательного была связана с такими далекими от психоанализа областями, как экономика. Однако, как показали авторы доклада, посвященного активизация творческого потенциала экономики, - заведующий кафедрой менеджмента Московского гуманитарного университета, доктор экономических наук, профессор Ю. Н. Царегородцев и магистрант Московского гуманитарного университета Ф. Н. Ермошкин, - история развития промышленности должна исследоваться, прежде всего, социологией и психологией. Это связано с тем, что производственные отношения - это отношения людей, чрезвычайно вариабельные. А значит, и производительность труда зависит не только от квалификации и трудолюбия работников, но и от свойств их психики, от ее адаптивности и способности к творчеству - то есть, человек и его психика могут рассматриваться в качестве источника прибавочной стоимости.

Экономике - в данном случае - экономике впечатлений как явлению культуры - был посвящен доклад Т. М. Гудимы, профессору кафедры философии, культурологии и политологии Московского гуманитарного университета, кандидату философских наук, доценту. Профессор отметила, что впечатление, основанное на эмоциональном постижении предмета 
культуры, становится важной составляющей его понимания. Это востребуется в процессе демонстрации образцов исторического наследия, а также в процессе развития целостных территорий, в которых воссоздаются не только артефакты, но и традиционная производственная деятельность и характер экономического развития.

По мнению многих исследователей, сегодня проблема бессознательного становится чрезвычайно актуальной в связи с формированием виртуальных, симуляционных реальностей.Как показала Е.Ю.Шакирова, профессор кафедры гуманитарных и социально-экономических дисциплин филиала ВУНЦ ВВС «ВВА имени профессора Н. Е. Жуковского и Ю. А. Гагарина» в г. Сызрани, член-корреспондент Академии военных наук, доктор философских наук, доцент, сознание и бессознательное играют активную роль в образовании виртуальных реальностей - естественной и искусственной, где первая есть мир значений и символов, формируемый человеком вокруг себя без опосредования техникой, вторая, соответственно, - собственно симуляция, создаваемая исключительно при помощи технических средств.

Общим итоговым обзором научного пути Анатолия Эммануиловича Воскобойникова завершила конференцию декан факультета культуры и искусства, заведующая кафедрой философии, культурологии и политологии МосГУ, доктор философских наук, доктор культурологии, професcop А. В. Костина. Она поблагодарила коллег, представивших проблематику бессознательного в самых разных ракурсах, в том числе в связи с деятельностью А. Э. Воскобойникова и развитием отечественной науки. Она акцентировала тот факт, что А. Э. Воскобойников был одним из первых отечественных исследователей, которые способствовали возвращению в российскую науку темы бессознательного - профессор участвовал в этом процессе, начиная с симпозиума в г. Тбилиси в 1979 г. Выступавшая очертила социальные и научные условия, в которых вызревал интерес А. Э. Воскобойникова к этой теме, отмечая и его материалистическое мышление, и страстную любовь к искусству и, в частности, к кинематографу, а также особую творческую свободу, которая присутствовала в Высшей комсомольской школе. Особое внимание в докладе было уделено становлению научной школы А. Э. Воскобойникова, которая сложилась как содружество единомышленников, связанных методологическим единством и родством духа.

Конференция показала, что проблематика бессознательного остается и на сегодняшний день одной из наиболее актуальных, и ее развитию будет посвящена дальнейшая творческая работа профессора А. Э. Воскобойникова и всех тех - аспирантов, докторантов, коллег, - кто принадлежит к этой научной школе. 


\section{СПИСОК ЛИТЕРАТУРЫ}

Ламажаа, Ч. К. (2007) Воскобойников Анатолий Эммануилович: «В моем доме луна, а не люстра...»// Знание. Понимание. Умение. № 4. C.207-215.

Ламажаа Чимиза Кудер-ооловна - доктор философских наук, заместитель директора Института фундаментальных и прикладных исследований Московского гуманитарного университета. Адрес: 111395, Россия, г. Москва, ул. Юности, д. 5, корп. 6. Тел.: +7 (499) 374-59-30. Эл.адрес: chlamazhaa@mosgu.ru

Костина Анна Владимировна - доктор философских наук, доктор культурологии, профессор, декан факультета культуры и искусства Московского гуманитарного университета. Адрес: 111395, Москва, ул. Юности, д. 5. Тел.: +7 (499) 374-61-81. Эл.адрес: Anna_Kostina@inbox.ru

Lamazhaa Chimiza Kuder-oolovna, Doctor of Philosophy, Deputy Director, Institute of Fundamental and Applied Studies, Moscow University for the Humanities. Postal address: 5, Yunosti St., Moscow, Russian Federation 111395. Tel.: +7 (499) 374-59-30. Email: chlamazhaa@mosgu.ru

Kostina Anna Vladimirovna, Doctor of Philosophy, Doctor of Culturology, Professor, Dean, Faculty of Culture and Art, Moscow University for the Humanities. Postal address: 5, Yunosti St., Moscow, Russian Federation 111395. Tel.: +7 (499) 374-61-81. E-mail: Anna_Kostina@inbox.ru

\section{Для циитирования:}

Ламажаа Ч. К., Костина А. В. Всероссийская научная конференция «Культура между Логосом и Мифом: к проблеме бессознательного» (к 80-летию А. Э. Воскобойникова) [Электронный ресурс] // Научные труды Московского гуманитарного университета. 2017. № 5. URL: http://journals. mosgu.ru/trudy/article/view/572 DOI: 10.17805/trudy.2017.5.10 (дата обращения: дд.мм.гг.). 